\title{
Relationship between Stress and Psychosomatic Complaints among Nurses in Tabarjal Hospital
}

\author{
Ibrahim Abdelrahim Ibrahim Humaida \\ Faculty of Arts \& Sciences, Aljouf University, Tabarjal, KSA \\ Email: ibrahim_humaida@hotmail.com
}

Received February 14, 2012; revised March 20, 2012; accepted April 18, 2012

\begin{abstract}
This research was conducted to examine the relationship between stress and psychosomatic complaints among nurses in Tabarjal hospital. To achieve this aim, the researcher used the descriptive method and selected a sample consisting of (56) nurses working in hospital through the simple random sampling technique. The respondents were requested to complete a questionnaire for rating of stress and the most common psychosomatic diseases. The collected data were analyzed statistically by using SPSS. The results revealed that the stress was dominant among nurses in Tabarjal hospital, the prevalence of psychosomatic complaints was significantly higher in nurses, and there was significant correlation between stress and psychosomatic complaints among nurses. Conclusion: This research confirmed the effect of strains on the prevalence of psychosomatic symptoms among nurses in Tabarjal hospital. Further, implications of the results were discussed on the light of some related researches.
\end{abstract}

Keywords: Stress; Psychosomatic Complaints; Nurses; Tabarjal Hospital

\section{Introduction}

Stress constitutes a potential threat to health and adjustment cause many serious physical complaints among human beings due to its direct effect on body's biological systems such as the nervous system, digestive system, respiratory system, and cardiovascular system.

There are different views regarding the impact of stress on cardiovascular disorders. Clinical data indicate that people with stress report higher levels of hypertension, angina pectoris, and heart attack due to persistent stressful situations.

There is no doubt that individuals who experience severe stress are most likely apt to display stress-related behaviors such as smoking, alcohol and drugs addiction. These behaviors have direct effects on the development of heart diseases in human beings. Stress is also responsible for the appearance of some gastrointestinal problems such as gastric and peptic ulcers, irritable bowel syndrome, and constipation.

Concerning the relationship between stress and psychosomatic complaints among nurses in general, many researches were conducted in different parts of the world. According to Kane PP (2005) [1], most causes of stress among nurses are: jobs do not finish on time, troublesome patients, relatives, overtime and insufficient pay. Psychosomatic disorders like acidity and back pain significantly increased in nurses are having higher stress scores.

Rita et al. (1984) [2] pointed out the effect of personality and professional variables on nurses, experienced stress. B. Piko (1999) [3], found some common psychosomatic symptoms among nurses (such as sleeping problems, tension headache and chronic fatigue), and Pamela et al. (2002) [4] identified causes and effects of nursing stress.

Based on the previous researches findings regarding stress among nurses and its effect on over all functioning, this present research is also an attempt to investigate the relationship between stress and prevalence of psychosomatic complaints among nurses in Tabrjal hospitalSaudi Arabia.

\subsection{Statement of the Research Problem}

Stress affects each person differently in both mental and physical ways. This statement may provoke many questions which need answers from researchers by conducting intensive researches to verify various hypotheses regarding the relationship between stress and psychosomatic diseases.

The present research seeks to answer the following questions as far as research problem is concerned:

1) Are nurses really suffering from stress?

2) Is there any correlation between stress and psychosomatic complaints among nurses in Tabarjal hospital? 


\subsubsection{Research Objectives}

1) To investigate the level of stress among nurses in Tabarjal hospital.

2) To find out if there is relationship between stress.

\subsubsection{Importance}

To identify the extent and sources of stress among nurses in a hospital is very important because stress in nurses affect their health and consequently cause negative and serious implication.

\subsubsection{Hypotheses}

1) Stress scores were high among nurses.

2) There was significant statistical correlation between stress and psychosomatic complaints.

\subsubsection{Location}

This research was carried out in Tabarjal hospital. Tabarjal is a small town located at the northern region of Saudi Arabia. That was in January 2012.

\section{Literature Review}

\subsection{Psychosomatic Disorders}

Psychosomatic disorders are diseases caused by stresses or they are somatic symptoms and sings that are not linked to any specific physiological dysfunction. It is true that any physical symptom (e.g. palpitation) can be psychosomatic in nature, the most common psychosomatic disorders occur as somatization disorders .Furthermore, psychological stresses can cause physical symptoms such as headache, hypertension, psychogenic impotence, and digestive problems [5].

In the Islamic era, the Muslim psychiatrist Ahmed Al-Balkhi (d.934) and Haly Abbas (d.994) established a conception of an illness owing to mind-body relationship. They emphasized that there should be mutual effect between a patient's physiology and psychology. They also correlated between health and illness [6].

In the beginnings of the $20^{\text {th }}$ century, Franze Alexander attempted to study the dynamic interaction between mind and body which is presently known as "psychosomatic" [7].

Sigmund Freud, the founder of psychosomatic approach, was also interested in psychosomatic illnesses and their treatment through psychological techniques [8].

In Germany, since 1970s, biosemiotic theory was developed as a theoretical foundation for psychosomatic medicine in order to describe and interpret different psychosomatic phenomena. At present, scientific concern about psychosomatic plastic surgery and its relation to therapy has increased [9].

\subsection{The Most Common Psychosomatic Disorders Due to Stress}

The most common psychosomatic disorders are: psychogenic pain, which appears in anywhere, in the body due to mind-body interaction. Persons under severe stress may suffer severe pain without any organic cause [10].

Hypochondria are also considered common psychosomatic disorders among people. Hypochondrium is defined as an excessive preoccupation or worry about having a serious disease, despite medical testing finds no any physical cause or defect. People who experience stress may have a persistent fear of having a serious and incurable medical illness [11].

There are some physical diseases that are directly linked to stresses of life [12], e.g. back pain, hypertension, peptic ulcer and irritable bowel syndrome [13].

There is an overlap between what is physical and what is psychosomatic; therefore, it is difficult in psychiatry to differentiate between somatoform and psychosomatic disorders. But in both, mental factors play an important role in the development and inducing such diseases [14].

It is worth noting that almost all physical illnesses have psychological factors that determine the etiology, prognosis, diagnosis, and treatment of psychosomatic disorders $[15,16]$.

In modern society, psychosomatic manifestations of illness are often attributed to life stresses [17].

Consequently, stress management is crucial step in the treatment and prevention of psychosomatic diseases.

\subsection{Meanings of the Term "Psychosomatic Illness" and Its Treatment}

The phrase psychosomatic illness is used to apply to illnesses that are now called somatization disorders and classified as stress-related disorders (WHO, ICD). For this reason, the field of psychosomatic medicine as a branch of psychiatry come out to deal with many psychosomatic diseases. Both medical and psychotherapeutic treatments are used to cure psychosomatic disorders [18].

\section{Research Methodology}

In this research, the descriptive correlation method was used to correlate between scores on stress and psychosomatic complaints in nurses. The researcher designed a questionnaire for rating stress, and a list containing the most common psychosomatic complaints.

\subsection{Instruments}

A pilot study was carried out by giving questionnaires to (20) nurses in order to verify reliability and validity of data collection devices for the present research.

The researcher was later applied these questionnaires 
to (56) nurses who work in Tabarjal main hospital. All of them responded and the data were collected.

Causes of stress in nurses were categorized under: work-related, and home-related stress. Level of stress were classified in terms of severity as shown on the Table 1.

Also, there was a check list containing the most common psychosomatic complaints among nurses as shown on the Table 2.

Nurses in this research were selected randomly from different units of the hospital .The selected sample consisted (56) respondents out of (120) which was the total working force in the hospital Table 3.

Table 1. Shows severity of stress.

\begin{tabular}{cc}
\hline Stress Levels & Score \\
\hline mild & Less than 13 \\
moderate & $13-25$ \\
severe & $26-37$ \\
burnout & More than 37 \\
\hline
\end{tabular}

Table 2. Shows a check list of psychosomatic complaints.

\begin{tabular}{lcc}
\hline Complaints & Present (Yes) & Absent (No) \\
\hline hypertension & 11 \\
headache & 12 \\
ulcers & 06 \\
bronchitis & 09 \\
back pain & 13 \\
eczema & 05 \\
\hline
\end{tabular}

Table 3. Shows demographic variables of the selected sample $(n=56)$.

\begin{tabular}{llcc}
\hline Age & Marital Status & No. & \% \\
\hline & Married & 22 & 39 \\
$\begin{array}{l}\text { Less than 25 } \\
26-34 \\
35+\end{array}$ & Single & 20 & 35 \\
& Divorced & 8 & 14 \\
Wex & Widowed & 6 & 12 \\
Men & & & \\
Women & & 24 & 43 \\
\hline
\end{tabular}

\subsection{Results \& Discussion}

In this part of research, the result of each hypothesis is presented and explained.

\subsubsection{Hypothesis (1) Nurses Scored Highly on Stress}

\subsubsection{The Result of Hypothesis (1)}

To verify this hypothesis, t-test for one sample was used as displayed on the Table 4.

It appears from the table that mean difference is significant at (0.000), this indicates that stress scores are high among the nurses.

\subsubsection{The Discussion of Hypothesis (1)}

This result was in line with the finding of B. Piko (1999) and Rita et al. (1984). The issue of occupation stress amongst health care professionals in general and nurses in particular is currently a major concern in health policy. According to researcher, stress denotes various psychosocial situations which tend to produce disorganization of behavior, including physical and mental illnesses.

Nurses all over the world work under stress as the nature of their work requires, it is true that many hospitals in Saudi Arabia characterized by conductive work atmosphere, nevertheless, nurses suffer and encounter stress. That is due to tremendous and frequent contact with patients who have different diseases. What causes stress among nurses as indicated by Pamela and James (2002) were functions of the type of unit on which they worked, levels of training, trait anxiety, and sociodemographic characteristics.

\subsubsection{Hypothesis (2) The Prevalence of Psychosomatic Complaints Was Significantly Higher in Nurses}

\subsubsection{The Result of Hypothesis (2) (Table 5)}

\subsubsection{The Discussion of Hypothesis (2)}

This result matched with the finding of Kane, P. (2009). Indeed, Western medical thinkers have long been aware of the mind's influence over the body, support for the psychosomatic complaints in general comes from the reality that the incidence of psychosomatic diseases among those subjected to severe stress.

Table 4. Shows t-test result to examine whether nurses scores high or low on stress.

\begin{tabular}{ccccccc}
\hline \multicolumn{1}{c}{ Test Value $=50$} \\
\hline & & & & & & \\
t & df & $\begin{array}{c}\text { Sig. } \\
\text { (2-tailed) }\end{array}$ & $\begin{array}{c}\text { Mean } \\
\text { Difference }\end{array}$ & $\begin{array}{c}\text { 95\% Confidence } \\
\text { Interval of the Difference }\end{array}$ \\
\cline { 5 - 6 } & & & & Lower & Upper \\
\hline Stress & 5.558 & 55 & .000 & 8.30000 & 5.2797 & 11.3203 \\
\hline
\end{tabular}


Table 5. Shows statistically significant parameters of the prevalence of the psychosomatic complaints derived from t-test.

\begin{tabular}{lccc}
\hline Parameter & & Mean & P-value \\
\hline \multirow{2}{*}{ Hypertension } & Present & 15.13 & 0.000 \\
Headache & Absent & 10.12 & \\
\multirow{2}{*}{ Ulcers } & Present & 14.11 & 0.000 \\
& Absent & 11.03 & \\
Bronchitis & Present & 16.10 & 0.000 \\
& Absent & 12.11 & \\
Back Pain & Present & 16.14 & 0.000 \\
& Absent & 8.12 & \\
Eczema & Present & 20.14 & 0.000 \\
& Absent & 7.13 & \\
\hline
\end{tabular}

3.2.3. Hypothesis (3) There Was Significant Correlation between Stress and Psychosomatic Complaints among Nurses

3.2.3.1. The Result of Hypothesis (3)

\begin{tabular}{llcc}
\hline & & Stress & $\begin{array}{c}\text { Psychosomatic } \\
\text { Complaints }\end{array}$ \\
\hline \multirow{4}{*}{ Stress } & $\begin{array}{l}\text { Pearson } \\
\text { Correlation }\end{array}$ & 1 & 0.88 \\
& $\begin{array}{l}\text { Sig. } \\
(2 \text {-tailed })\end{array}$ & & 0.01 \\
& $\mathrm{~N}$ & 56 & 56 \\
Psychosomatic & $\begin{array}{l}\text { Correlation } \\
\text { Complaints }\end{array}$ & 0.88 & 1 \\
& $\begin{array}{l}\text { Sig. } \\
(2 \text {-tailed })\end{array}$ & 0.01 & 56 \\
& $\mathrm{~N}$ & 56 & \\
\hline
\end{tabular}

It appears from the table above that a significant correlation found between stress and psychosomatic complaints in nurses.

\subsubsection{The Discussion of Hypothesis (3)}

In considering the role of stress in the etiology of psychosomatic complaints among nurses, it is first necessary to establish a statistically significant relationship between the occurrence of stress and manifestations of the complaints and determine whether the stress comes under the category of essential causes leading to psychosomatic illnesses.

The link between psychosomatic complaints and stress can be understood in the light of the fact that some physical diseases are believed to have derived from the stresses and strains of everyday living .This is the case, for example, of lower back pain and high blood pressure, which appear to be partly related to stresses in every day life.

\section{Conclusion}

In researcher's view, social support and the psychosocial work environment should be improved in medical care institutions.

\section{Recommendations}

1) Supportive relationships may reduce the occurrence of high stress level among nurses.

2) To provide nurses with counseling services.

3) To follow up nurses' mental health care.

\section{Suggestions for Future Researches}

1) To carry out research on the impact of psychosocial support on nurses.

2) A cross-sectional survey on the prevalence of the most psychosomatic symptoms among physicians.

\section{REFERENCES}

[1] P. P. Kane, "Stress Causing Psychosomatic Illness among Nurses," Indian Journal of Occupational and Environmental Medicine, Vol. 13, No. 1, 2009, pp. 28-32. doi:10.4103/0019-5278.50721

[2] R. E. Numerof and M. N. Abrams, "Sources of Stress among Nurses: An Empirical Investigation," Journal of Human Stress, Vol. 10, No. 2, 1984, pp. 88-100.

[3] B. Piko, "Work-Related Stress among Nurses: A Challenge for Health Care Institutions," The Journal of the Royal Society for the Promotion of Health, Vol. 119, No. 3, 1999, pp. 156-162. doi:10.1177/146642409911900304

[4] P. Gray and J. G. Anderson, "Stress among Hospital Nursing Staff: It Is Causes and Effects,” Medical Psychology, Vol. 15, 2002, pp. 639-647.

[5] J. L. Levenson, "Essentials of Psychosomatic Medicine," American Psychiatric Press Inc., 2006.

[6] N. Deuraseh and M. Abu Talib, "Mental Health in Islamic Medical Tradition,” The International Medical Journal, Vol. 4, No. 2, 2005, pp. 76-79.

[7] G. Asaad, "Psychosomatic Disorders: Theoretical and Clinical Aspects,” Brunner-Mazel, 1996, pp. 129-130.

[8] E. Erwin, "The Freud Encyclopedia: Theory, Therapy and Culture,” Routledge, 2002, pp. 245-246.

[9] J. E. Beck, “A Developmental Perspective on Functional Somatic Symptoms,” Journal of Pediatric Psychology, Vol. 33, No. 5, 2008, pp. 547-562. doi:10.1093/jpepsy/jsm113

[10] J. Sarno, “The Divided Mind,” Regan Books, GI Consult, Perforated Peptic Ulcer, 2006, Retrieved 26 August 2007. 
http://www.emedmag.com/html/pre/gic/consults/071503. asp

[11] R. N. Melmed, "Mind, Body and Medicine: An Integrative Text,” Oxford University Press Inc., Oxford, 2001, pp. 191-192.

[12] V. A. Skumin, "Borderline Mental Disorders in Chronic Diseases of the Digestive System in Children and Adolescents," Zhurnal Nevropatologii i Psikhiatrii Imeni SS Korsakova Moscow Russia 1952, Vol. 91, No. 8, 1991, pp. 81-84.

[13] H. Treasaden, B. K. Puri and P. J. Laking, "Textbook of Psychiatry,” Churchill Livingstone, 2002, p. 7.

[14] M. Greco, "Illness as a Work of Thought: Foucauldian Perspective on Psychosomatics," Routledge, 1998, pp.
1-3, 112-116.

[15] T. N. Wise, "Update on Consultation-Liaison Psychiatry (Psychosomatic Medicine)," Current Opinion in Psychiatry, Vol. 21, No. 2, 2008, pp. 196-200. doi:10.1097/YCO.0b013e3282f393ae

[16] J. Lacey, "Differential Emphasis in Somatic Response to Stress: An Experimental Study," Psychosomatic Medicine, Vol. 14, 1998, pp. 71-81.

[17] E. Shorter, "From Paralysis to Fatique: A History of Psychosomatic Illness in the Modern Era,” Free Press, New York, 1992.

[18] R. Porter, "Psychosomatic Disorders: Historical Perspectives,” Oxford, 1995. 